\title{
Interfacial partitioning behaviour of bovine serum albumin in polymer-salt aqueous two-phase system
}

\begin{abstract}
A relationship is proposed for the interfacial partitioning of protein in poly (ethylene glycol) (PEG)-phosphate aqueous two-phase system (ATPS). The relationship relates the natural logarithm of interfacial partition coefficient, $\ln G$ to the PEG concentration difference between the top and bottom phases, $\Delta[\mathrm{PEG}]$, with the equation $\ln \mathrm{G}=\mathrm{A} \Delta[\mathrm{PEG}]+\mathrm{B}$. Results showed that this relationship provides good fits to the partition of bovine serum albumin (BSA) in ATPS which is comprised of phosphate and PEG of four different molecular weight $1450 \mathrm{~g} / \mathrm{mol}, 2000 \mathrm{~g} / \mathrm{mol}, 3350 \mathrm{~g} / \mathrm{mol}$ and $4000 \mathrm{~g} / \mathrm{mol}$, with the tie-line length (TLL) in the range of $44-60 \%(\mathrm{w} / \mathrm{w})$ at $\mathrm{pH} 7.0$. The decrease of A values with the increase of PEG molecular weight indicates that the correlation between $\ln \mathrm{G}$ and $\Delta[\mathrm{PEG}]$ decreases with the increase in PEG molecular weight and the presence of protein-polymer hydrophobic interaction. When temperature was increased, a non-linear relationship of $\ln G$ inversely proportional to temperature was observed. The amount of proteins adsorbed at the interface increased proportionally with the amount of BSA loaded whereas the partition coefficient, $\mathrm{K}$ remained relatively constant. The relationship proposed could be applied to elucidate interfacial partitioning behaviour of other biomolecules in polymer-salt ATPS.
\end{abstract}

Keyword: Aqueous two-phase system; Interfacial partition; Statistical mechanics; Bioseparation; Protein recovery; Purification. 